\title{
Effects of Phase Constitution and Microstructure on Energy Storage Properties of Barium Strontium Titanate Ceramics
}

Yong Jun $\mathrm{Wu}^{\mathrm{a}, \mathrm{b}, \mathrm{c}}$, Yu Hui Huang ${ }^{\mathrm{a}, \mathrm{b}, \mathrm{c}}$, Nan Wang ${ }^{\mathrm{a}, \mathrm{b}, \mathrm{c}}$, Juan $\mathrm{Li}^{\mathrm{d}, *}$, Mao Seng Fu ${ }^{\mathrm{e}}$, Xiang Ming Chen ${ }^{\mathrm{b}}$

${ }^{\mathrm{a}}$ State Key Laboratory of Silicon Materials, Zhejiang University, Hangzhou 310027, China.

${ }^{\mathrm{b}}$ Laboratory of Dielectric Materials, School of Materials Science and Engineering, Zhejiang University, Hangzhou 310027, China

${ }^{\mathrm{c} C y r u s ~ T a n g}$ Center for Sensor Materials and Applications, Zhejiang University, Hangzhou 310027, China

${ }^{\mathrm{d}}$ College of Materials Science and Engineering, Zhejiang University of Technology, Hangzhou 310006, China

${ }^{e}$ School of Materials Science and Engineering, Northwestern Polytechnical University, Xi'an 710072, China

\begin{abstract}
Barium strontium titanate $\left(\mathrm{Ba}_{0.3} \mathrm{Sr}_{0.7} \mathrm{TiO}_{3}, \mathrm{BST}\right)$ ceramics have been prepared by conventional sintering (CS) and spark plasma sintering (SPS). The effects of phase constitution and microstructure on dielectric properties, electrical breakdown process and energy storage properties of the BST ceramics were investigated. The X-ray diffraction analysis and dielectric properties measurements showed that the cubic and tetragonal phase coexisted in the SPS sample while the CS sample contained only tetragonal phase. Much smaller grain size, lower porosity, fewer defects and

\footnotetext{
* Corresponding author.

E-mail address: juanli@zjut.edu.cn (J. Li).
} 
dislocation were observed in SPS samples, which greatly improved the electrical breakdown strength of the $\mathrm{Ba}_{0.3} \mathrm{Sr}_{0.7} \mathrm{TiO}_{3}$ ceramics. The enhanced breakdown strength of the SPS samples resulted in an improved maximum electrical energy storage density of $1.13 \mathrm{~J} / \mathrm{cm}^{3}$ which was twice as large as that of the CS sample $\left(0.57 \mathrm{~J} / \mathrm{cm}^{3}\right)$. Meanwhile, the energy storage efficiency was improved from $69.3 \%$ to $86.8 \%$ by using spark plasma sintering.

Keywords: Barium strontium titanate; Microstructure; Spark plasma sintering; Energy storage

\section{Introduction}

Electric energy storage materials have been receiving much attention because they play a key role in efficient, clean and versatile use of energy [1]. In particular, while conventional batteries and solid oxide fuel cells offer higher energy density, capacitors possess higher power density and much faster charge and discharge rates [2]. This is essential for pulsed power applications and regenerative braking system $[3,4]$. In order to meet the increasing need for improving the mass- and volume-efficiency of energy storage components, the energy density of capacitors must be increased [5]. At least two approaches are utilized to address this issue. One is the use of supercapacitors based on electrolytic solution and the other is the use of solid state capacitors based on dielectrics [3,6]. Various materials such as oxides, glass and polymers have been extensively investigated to optimize them as candidates for high energy density dielectrics [7-13]. Generally, the involved dielectrics are focused on linear dielectrics, ferroelectrics and antiferroelectrics. The energy storage density $J$ is described by [14] 


$$
J=\int_{0}^{E} E \mathrm{~d} P=\int_{0}^{E} \varepsilon_{0} \varepsilon_{r}(E) E \mathrm{~d} E
$$

where $J$ is the energy storage density $\left(\mathrm{J} / \mathrm{m}^{3}\right), E$ is the applied electric field $(\mathrm{V} / \mathrm{m}), \varepsilon_{0}$ is the permittivity of free space $\left(8.854 \times 10^{-12} \mathrm{~F} / \mathrm{m}\right), \mathrm{d} P$ is the change in polarization induced in the dielectric by the applied field and $\varepsilon_{r}(E)$ is the electric-field-dependent permittivity $\left(\varepsilon_{r}(E)=\varepsilon(E) / \varepsilon_{0}\right)$. For linear dielectrics, the permittivity is not electric-field-dependent and the energy storage density can be derived as

$$
J=\frac{1}{2} \varepsilon_{0} \varepsilon_{r} E^{2}
$$

As can be seen from these equations, to store more energy in a dielectric, a high permittivity (high $\varepsilon_{r}$ ) and a high breakdown strength allowing the application of high $E$ are required.

High energy storage density can be achieved in some linear dielectrics, such as mica, glass, diamond-like carbon films and several polymer films [2,9-13]. These materials exhibit high breakdown strength, but suffer from low dielectric constant. Ceramics, on the other hand, have high/giant dielectric constant, but are limited to relatively low breakdown strength $[14,15]$. Over years, a lot of research has been focused on improving breakdown strength of linear dielectric ceramics for high energy density storage. The $\mathrm{Ba}_{1-\mathrm{x}} \mathrm{Sr}_{\mathrm{x}} \mathrm{TiO}_{3}$ (BST) is one of the most popular materials because of its excellent dielectric properties and the ability to engineer different dielectric behavior by mixing with other components or forming composite structure. Glass and/or oxides, such as $\mathrm{Al}_{2} \mathrm{O}_{3}$ and $\mathrm{MgO}$, have been adopted to refine the microstructure of BST materials and thus increase the breakdown strength [16-18].

In the past decades, spark plasma sintering, which allows for quick densification 
has been found to be a useful and efficient method in tailoring the microstructure of ceramics [19-21]. The advantages of SPS method, such as low sintering temperature, short sintering time and microscopic electrical discharges between particles, make it suitable to control the grain size and grain boundary of ceramics and to tailor the configuration and interface of composites [22-24].

In this paper, barium strontium titanate ceramics were prepared and the effects of phase constitution and microstructure on dielectric properties, electrical breakdown process and electrical energy storage properties of BST ceramics were investigated in detail.

\section{Experimental Procedure}

$\mathrm{Ba}_{0.3} \mathrm{Sr}_{0.7} \mathrm{TiO}_{3}$ powders were synthesized by the conventional solid state reaction method. Stoichiometric mixtures of $\mathrm{SrCO}_{3}$ (>99.95\%, Aladdin), $\mathrm{BaCO}_{3}$ (>99.99\%, Shanghai Chemical Reagent) and $\mathrm{TiO}_{2}(>99.99 \%$, Shanghai Chemical Reagent) were ball milled with zirconia balls in distilled water for $24 \mathrm{~h}$ and calcined at $1150^{\circ} \mathrm{C}$ in air for $3 \mathrm{~h}$. To prepare $\mathrm{Ba}_{0.3} \mathrm{Sr}_{0.7} \mathrm{TiO}_{3}$ ceramics by the conventional sintering method (CS), the calcined powders were mixed with a poly(vinylalacohol) binder solution and uniaxially pressed into disk samples with a diameter of $12.5 \mathrm{~mm}$. After removal of the binder, the green disks were sintered at $1400^{\circ} \mathrm{C}$ for $3 \mathrm{~h}$ in an alumina crucible, and were called CM samples. To prepare $\mathrm{Ba}_{0.3} \mathrm{Sr}_{0.7} \mathrm{TiO}_{3}$ ceramics by SPS, the calcined powders were placed in a graphite die and sintered at $1000^{\circ} \mathrm{C}$ for 5 min under a vacuum of $6 \mathrm{~Pa}$ with an SPS apparatus (SPS-1050, SPS Syntex Inc., Kanagawa, 
Japan). During the period of heating, a pressure of $30 \mathrm{MPa}$ was applied to the sample. The heating rate was $100^{\circ} \mathrm{C} / \mathrm{min}$ from room temperature to $900^{\circ} \mathrm{C}, 40^{\circ} \mathrm{C} / \mathrm{min}$ from $900^{\circ} \mathrm{C}$ to $980^{\circ} \mathrm{C}$, and $20^{\circ} \mathrm{C} / \mathrm{min}$ from $980^{\circ} \mathrm{C}$ to $1000^{\circ} \mathrm{C}$. All the spark plasma sintered samples were polished and thermally treated at $1000^{\circ} \mathrm{C}$ for $2 \mathrm{~h}$ in air and were called SPS samples. Both the CS samples and the SPS samples were then polished and coated on each major face with Au electrodes.

The crystalline phases of sintered samples were characterized by X-ray diffraction (XRD, D/MAX 2550/PC, Rigaku, Tokyo, Japan) using $\mathrm{Cu} K_{\alpha}$ radiation. The microstructures were observed from the thermally etched surfaces with field emission scanning electron microscopy (SEM, S-4800, Hitachi, Tokyo, Japan). The grain size of the sintered samples was determined from the SEM micrographs using the linear intercept method. The samples for transmission electron microscopy were prepared via the ultrasonic cutting of disks $3 \mathrm{~mm}$ in diameter and mechanical polishing to a thickness of about $100 \mu \mathrm{m}$. The central portions of the disks were reduced further to about $10 \mu \mathrm{m}$ by mechanical dimpling (Model656, Gatan, SanFrancisco, CA, USA) followed by final polishing. The final perforation of the BST sample was conducted via precision argon-ion milling (Model691, Gatan, San Francisco, CA, USA), using an acceleration voltage of $4 \mathrm{kV}$. The TEM images were obtained at $300 \mathrm{kV}$ by a transmission electron microscope (TEM, Tecnai F30G2, FEI, Hillsboro, OR, USA).

The dielectric properties were evaluated with a broadband dielectric spectrometer (Turnkey Concept 80, Novocontrol Technologies GmbH \& Co. KG, 
Hundsangen, Germany) in a broad range of temperature (140-400 K) and frequency (100 Hz-1 MHz) with a heating rate of $2 \mathrm{~K} / \mathrm{min}$. A ferroelectric test system (Premier II, Radiant Tech. Inc., NM, USA) were used for $P$ - $E$ loops measurement. The energy storage densities and efficiencies were calculated from the $P-E$ loops.

\section{Results and Discussion}

\subsection{Phase constitution and microstructure observation}

Figure 1 shows the XRD patterns of the CS sample and SPS sample. All the diffraction peaks for both samples can be indexed. As shown in Figure 1(b), the split of diffraction peaks at high angles corresponding to the tetragonal phase are only found in the CS sample. The XRD analysis indicates that the CS sample consists of only the tetragonal BST phase, while a high content of the cubic BST phase exists in the SPS sample. The cubic BST phase in the SPS sample may present linear dielectric properties, which is beneficial for the reduction of remnant polarization and the improvement of the energy storage efficiency.

SEM micrographs on the thermally etched surfaces and fracture surfaces of the CS sample and SPS sample are shown in Figure 2. The CS sample exhibits inhomogeneous microstructures where some pores can be discerned from the thermally etched surfaces. In contrast, the SPS sample presents a uniform, fine and dense microstructure where the average grain size is $880 \mathrm{~nm}$. As shown in Figure 2(b) and 2(d), clear grain boundaries can be observed in the SPS sample, whereas they are hard to distinguish in the CS sample. This indicates different fracture mechanisms in 
these two samples: transcrystalline fracture in the CS sample due to abnormal grain growth and intergranular fracture in the SPS sample. Figure 3(a) and (b) show the TEM micrographs of the $\mathrm{Ba}_{0.3} \mathrm{Sr}_{0.7} \mathrm{TiO}_{3}$ ceramics prepared by the conventional method and spark plasma sintering, respectively. It can be observed that there are fewer dislocations and defects in the SPS sample. Previous studies reported that a high concentration of dislocations in ceramics may lead to the possibility of coalescence and the formation of cracks under very strong electric fields [25]. Therefore, fewer dislocations in the SPS sample may contribute to the enhanced breakdown strength.

\subsection{Dielectric properties}

Figure 4 shows the temperature dependence of the dielectric constant and dielectric loss at various frequencies for the $\mathrm{Ba}_{0.3} \mathrm{Sr}_{0.7} \mathrm{TiO}_{3}$ ceramics. As shown in Figure 4(a), the CS sample exhibits sharp dielectric peaks at the Curie temperature $(167 \mathrm{~K})$, which is a typical dielectric behavior of normal ferroelectrics. In addition, the maximum in the dielectric loss coincides with the maximum in the dielectric constant, indicating that the CS sample undergoes a structural phase transition which corresponds to the cubic-tetragonal phase transition. For the SPS sample, the dielectric constant around the Curie temperature noticeably decreases and the dielectric peaks become wider. The enlarged figure in Figure 4(c) shows that the Curie temperature of the SPS sample is approximately $150 \mathrm{~K}$, which is lower than that of the CS sample. The different dielectric behavior of the SPS samples can be ascribed to the different phase constitutions and grain sizes. The existence of the cubic phase in the SPS sample significantly decreases the maximum dielectric constant at 
the dielectric peaks. The decrease of grain size in the SPS samples implies an increase of grain boundary layer contents. The grain boundary layer is usually considered a low-permittivity nonferroelectric phase, which also results in the depression of the dielectric constant [26]. The wide dielectric peak at the Curie temperature of the SPS sample indicates that the phase transition becomes diffuse. This can be attributed to the lack of sufficient chemical diffusion and increased internal stress during fast sintering and cooling [27-29].The Curie point shifting to the lower temperature in the SPS sample is mainly due to the smaller grain size. These results obtained in the SPS sample in this study are in agreement with the general behaviors reported for $\mathrm{BaTiO}_{3}$ [30], $\mathrm{BiScO}_{3}-\mathrm{PbTiO}_{3}$ [31], and $\mathrm{Bi}_{3.15} \mathrm{Nd}_{0.85} \mathrm{Ti}_{3} \mathrm{O}_{12}$ [32]. It is also worth noting that good temperature-stability was obtained in the SPS sample. Particularly at the operation temperature $(300 \mathrm{~K})$ and frequency $(50 \mathrm{~Hz}$ or $60 \mathrm{~Hz})$ for electrical energy storage, the dielectric loss of the SPS sample can be as low as 0.0025 , while it is much higher in the CS sample (0.0220). This is a significant benefit for reducing the energy loss and improving the energy storage efficiency.

\subsection{Electrical breakdown and energy storage properties}

A series of polarization-electric field $(P-E)$ loops at room temperature and $60 \mathrm{~Hz}$ ofBa $\mathrm{B}_{0.3} \mathrm{Sr}_{0.7} \mathrm{TiO}_{3}$ ceramics at various electric fields are shown in Fig. 5. A nearly linear $P-E$ behavior is observed for the SPS sample. The maximum applicable electric field (close to the dielectric breakdown strength, DBS)of the CS sample and the SPS sample is $140 \mathrm{kV} / \mathrm{cm}$ and $230 \mathrm{kV} / \mathrm{cm}$, respectively. Gerson et al. reported that the amount of porosity and defects and the size of voids and microcracks in the ceramics, 
which act as initiation points for breakdown, are important to the DBS in dielectrics [33].As shown in Fig. 2 and Fig. 3, the significantly enhanced maximum applicable electric field of the SPS sample can be ascribed to its low porosity, small size of voids and fewer defects and dislocations. A more straightforward analysis of the dielectric breakdown process was performed using SEM images (see Fig. 6). It is known that there are three main forms of solid-dielectric breakdown: electrothermal breakdown, electrochemical breakdown, and electrical breakdown. The first two forms of breakdown usually develop slowly over time while electrical breakdown occurs in a relatively short time $\left(10^{-7} \mathrm{sec}\right.$ or less) [25].As shown in Fig. 6(a) and 6(c), clear breakdown channels are observed on the fracture surfaces of both the CS and SPS samples. These channels are probably the shortest path between the electrodes for electron injection, causing electron avalanches and dielectric breakdown. As shown in Figure 6(b), it is clear that electrical breakdown tends to occur at pores and voids where the electric current can penetrate through the interior of abnormal large grains. However, in Figure 6(d), the high electric field appears to cause the melting of grains when the electrical breakdown occurs in the SPS sample. It has been reported that the melting of grains or crystals may lead to the increase of conductivity [25]. Therefore, it can be concluded that the melting of grains is the main form of destroying the insulativity in the dense ceramics with uniform and fine grains while electrical breakdown occurs at relative low-density ceramics with pores, voids, defects and abnormal grain growth.

As shown in Fig. 5, the electrical energy density charge $\left(J_{c}\right)$ is equal to the 
integral of the area enclosed by the charge curve and $y$-axis. The electrical energy density discharge $\left(J_{d}\right)$ is equal to the integral of the area enclosed by the discharge curve and $y$-axis. The unreleased energy density or the energy loss is equal to the integral of the area enclosed by the charge and discharge curve and $y$-axis. The ratio $J_{d} / J_{c}$ can be used to evaluate the energy storage efficiency $(\eta)$ [34]. The maximum energy storage density of $\mathrm{Ba}_{0.3} \mathrm{Sr}_{0.7} \mathrm{TiO}_{3}$ ceramics is represented by the red shadow area in Fig. 5. It is clear that the SPS sample possesses a much higher maximum energy storage density. The calculated energy storage densities for BST ceramics as a function of electric field are shown in Fig. 7. The $\mathrm{Ba}_{0.3} \mathrm{Sr}_{0.7} \mathrm{TiO}_{3}$ ceramics prepared by the conventional method and spark plasma sintering exhibit very similar energy storage densities at low electrical field. The maximum energy storage density of the SPS sample is $1.13 \mathrm{~J} / \mathrm{cm}^{3}$, which is approximately two times that of the CS sample. As represented in Eq. (2), the energy storage density in a linear dielectric is proportional to the product of the dielectric constant and square of the dielectric breakdown strength. The increase of dielectric breakdown strength of the SPS sample contributes to the significant enhancement of the energy storage density. Furthermore, as shown in Fig. 5, the energy storage efficiency of $\mathrm{Ba}_{0.3} \mathrm{Sr}_{0.7} \mathrm{TiO}_{3}$ ceramics improves from $69.3 \%$ to $86.8 \%$ by using spark plasma sintering. This can be attributed to the slimmer $P$-E loops with very low remnant polarization of the SPS sample.

\section{Conclusion}

The phase constitution, microstructure, dielectric properties, electrical breakdown process and electric energy storage properties of $\mathrm{Ba}_{0.3} \mathrm{Sr}_{0.7} \mathrm{TiO}_{3}$ ceramics 
prepared by spark plasma sintering were compared with that of the ceramics prepared by conventional sintering method. Curie point shifting towards lower temperature, a depression of the maximum dielectric constant at $T_{c}$ and low dielectric loss at room temperature were observed for the SPS samples due to the much smaller grain size and the existence of cubic phase. By using spark plasma sintering, the maximum energy storage density and the energy storage efficiency of the $\mathrm{Ba}_{0.3} \mathrm{Sr}_{0.7} \mathrm{TiO}_{3}$ ceramics were improved from 0.57 to $1.13 \mathrm{~J} / \mathrm{cm}^{3}$ and $69.3 \%$ to $86.8 \%$, respectively. The significant enhancement in energy storage properties can be attributed to the low porosity, fewer defects and dislocation, and small size of voids in the SPS sample.

\section{Acknowledgments}

This work was financially supported by National Science Foundation of China under Grant Nos. 51302245 and 51572237, Chinese National Basic Research Program under grant number 2015CB654601, the Specialized Research Fund for the Doctoral Program of Higher Education of China under Grant No. 20130101110085, Zhejiang Provincial Natural Science Foundation under Grant No. LZ17E020003, and Zhejiang Provincial Top Key Discipline of New Materials and Process Engineering.

\section{References}

1. C. Liu, F. Li, L.P. Ma, H.M. Cheng, Advanced materials for energy storage, Adv. Energy Mater. 22 (2010) E28-E62.

2. S.A. Sherrill, P. Banerjee, G.W. Rubloff, S.B. Lee, High to ultra-high power electrical energy storage, Phys. Chem. Chem. Phys. 13 (2011) 20714-23. 
3. H.A. Sher, K.E. Addoweesh, Power storage options for hybrid electric vehicles-a survey, J. Renew Sustain. Ener. 4 (2012) 0527015.

4. B. Xu, V.R. Cooper, D.J. Singh, Y.P. Feng, Relationship between bond stiffness and electrical energy storage capacity in oxides: density functional calculations for $\mathrm{h}-\mathrm{La}_{2} \mathrm{O}_{3}, \mathrm{MgO}$, and $\mathrm{BeO}$, Phys. Rev. B 83 (2011) 0641156.

5. D.M. Baechle, D.J. O'Brien, E.D. Wetzel, Structural dielectrics for multifunctional capacitors, Proc. of SPIE (2008) 6929.

6. M. Winter, R.J. Brodd, What are batteries, fuel cells, and supercapacitors? Chem. Rev. 104 (2004) 4245-69.

7. Z. Song, H.X. Liu, S.J. Zhang, Z.J. Wang, Y.T. Shi, H. Hao, M.H. Cao, Z.H. Yao, Z.Y. Yu, Effect of grain size on the energy storage properties of $\left(\mathrm{Ba}_{0.4} \mathrm{Sr}_{0.6}\right) \mathrm{TiO}_{3}$ paraelectric ceramics, $\mathrm{J}$. Eur. Ceram. Soc. 34 (2014) 1209-17.

8. Q. Xu, T.M. Li, H. Hao, S.J. Zhang, Z.J. Wang, M.H. Cao, Z.H. Yao, H.X. Liu, Enhanced energy storage properties of $\mathrm{NaNbO}_{3}$ modified $\mathrm{Bi}_{0.5} \mathrm{Na}_{0.5} \mathrm{TiO}_{3}$ based ceramics, J. Eur. Ceram. Soc. 35 (2015) 545-53.

9. N.J. Smith, B. Rangarajan, M.T. Lanagan, C.G. Pantano, Alkali-free glass as a high energy density dielectric material, Mater. Lett. 63 (2009) 1245-48.

10. C Yang, Y Lin, CW Nan, Modified carbon nanotube composites with high dielectric constant, low dielectric loss and large energy density, Carbon 47 (2009) 1096-1101.

11. P. Khanchaitit, K. Han, M.R. Gadinski, Q. Li, Q. Wang, Ferroelectric polymer networks with high energy density and improved discharged efficiency for dielectric energy storage, Nat. Commun. 26 (2013) 3845. 
12. X. Huang, P. Jiang, Core-Shell structured high- k polymer nanocomposites for energy storage and dielectric applications, Adv. Mater. 27 (2015) 546-54.

13. K. Yu, Y. Niu, Y. Zhou, Y. Bai, H. Wang, Nanocomposites of surface-modified $\mathrm{BaTiO}_{3}$ nanoparticles filled ferroelectric polymer with enhanced energy density, J. Am. Ceram. Soc. 96 (2013) 2519-24.

14. N.H. Fletcher, A.D. Hilton, B.W. Ricketts, Optimization of energy storage density in ceramic capacitors, J. Phys. D: Appl. Phys. 29 (1996) 253-8.

15. X.H. Hao, A review on the dielectric materials for high energy-storage application, J. Adv. Dielectr. 3 (2013) 1330001.

16. X.R. Wang, Y. Zhang, X.Z. Song, Z.B. Yuan, T. Ma, Q. Zhang, C.S. Deng, T.X. Liang, Glass additive in barium titanate ceramics and its influence on electrical breakdown strength in relation with energy storage properties, J. Eur. Ceram. Soc. 32 (2012) 559-67.

17. D. Yi, J.C. Yuan, H.Y. Liu, Y. Shen, Y.H. Lin, C.W. Nan, X. Xi, J.L. He, Influence of $\mathrm{Al}_{2} \mathrm{O}_{3}$ additive on the dielectric behavior and energy density of $\mathrm{Ba}_{0.5} \mathrm{Sr}_{0.5} \mathrm{TiO}_{3}$ ceramics, $\mathrm{J}$. Electroceram. 29 (2012) 95-98.

18. Y.H. Huang, Y.J. Wu, W.J. Qiu, J. Li, X.M. Chen, Enhanced energy storage density of $\mathrm{Ba}_{0.4} \mathrm{Sr}_{0.6} \mathrm{TiO}_{3}-\mathrm{MgO}$ composite prepared by spark plasma sintering, J. Eur. Ceram. Soc. 35 (2015) 1469-76.

19. W. Chen, U.A. Tamburini, J.E. Garay, J.R. Groza, Z.A. Munir, Fundamental investigations on the spark plasma sintering/synthesis process I. Effect of dc pulsing on reactivity, Mater. Sci. Eng. A 394 (2005) 132-138.

20. U.A. Tamburini, S. Gennan, J.E. Garay, Z.A. Munir, Fundamental investigations on the spark plasma sintering/synthesis process II. Modeling of current and temperature distributions, Mater. Sci. Eng. A 394 (2005) 139-148. 
21. Y.J. Wu, J. Li, X.M. Chen, K. Kakegawa, Densification and microstructures of $\mathrm{PbTiO}_{3}$ ceramics prepared by spark plasma sintering, Mater. Sci. Engineer. A 527 (2010) 5157-60.

22. Y.J. Wu, N. Wang, S.Y. Wu, X.M. Chen, Transparent barium strontium titanate ceramics prepared by spark plasma sintering, J. Am. Ceram. Soc. 94 (2011) 1343-45.

23. L. Gao, J.S. Hong, H. Miyamoto, S.D.D.L. Torre, Bending strength and microstructure of $\mathrm{Al}_{2} \mathrm{O}_{3}$ ceramics densified by spark plasma sintering, J. Eur. Ceram. Soc. 20 (2000) 2149-52.

24. X.Q. Liu, T.T. Chen, M.S. Fu, Y.J. Wu, X.M. Chen, Electrocaloric effects in spark plasma sintered $\mathrm{Ba}_{0.7} \mathrm{Sr}_{0.3} \mathrm{TiO}_{3}$-based ceramics: effects of domain sizes and phase constitution, Ceram. Int. 40 (2014) 11269-76.

25. G.A. Vorob'ev, N.S. Nesmelov, Electric breakdown in solid dielectrics, Russian Phys. J. 22 (1979) 70-80.

26. H. Xue, Z.X. Xiong, The structure and dielectric tunable properties of fine-grained $\mathrm{Ba}_{0.6} \mathrm{Sr}_{0.4} \mathrm{TiO}_{3}$ ceramics prepared by spark plasma sintering, J. Am. Ceram. Soc. 90 (2007) 2653-56.

27. W.R. Buesem, L.E. Cross, A.K. Goswami, Phenomenological theory of high permittivity in fine-grained barium titanate, J. Am. Ceram. Soc. 49 (1966) 33-36.

28. R.Z. Zuo, T. Granzow, L.D.C. upascu, J. Rodel, PMN-PT ceramics prepared by spark plasma sintering, J. Am. Ceram. Soc. 90 (2007) 1101-06.

29. M. Eriksson, H.X. Yan, G. Viola, H. Ning, D. Gruner, M. Nygren, M.J. Reece, Z.J. Shen, Ferroelectric Domain Structures and Electrical Properties of Fine-Grained Lead-Free Sodium Potassium Niobate Ceramics, J. Am. Ceram. Soc. 94 (2011) 3391-6.

30. Z. Zhao, V. Buscaglia, M. Viviani, M.T. Buscaglia, L. Mitoseriu, A. Testino, M. Nygen, M. Johnsson, P. Nanni, Grain-size effects on the ferroelectric behavior of dense nanocrystalline $\mathrm{BaTiO}_{3}$ ceramics, Phys. Rev. B 70 (2004) 024107.

31. T. Hungria, H. Amorin, M. Alguero, A. Castro, Nanostructured ceramics of $\mathrm{BiScO}_{3}-\mathrm{PbTiO}_{3}$ with tailored grain size by spark plasma sintering, Scripta Mater. 64 (2011) 97-100.

32. H.T. Zhang, H.X. Yan, H.P. Ning, M.J. Reece, M. Eriksson, Z.J. Shen, Y.M. Kan, P.L. Wang, The grain size effect on the properties of aurivillius phase $\mathrm{Bi}_{3.15} \mathrm{Nd}_{0.85} \mathrm{Ti}_{3} \mathrm{O}_{12}$ ferroelectric 
ceramics, Nanotechnology 20 (2009) 38570838.

33. R. Gerson, T.C. Marshall, Dielectric breakdown of porous ceramics, J. Appl. Phys. 30 (1959) 1650.

34. Y. Zhang, J.J. Huang, T. Ma, X.R. Wang, C.S. Deng, X.M. Dai, Sintering temperature dependence of energy-storage properties in $(\mathrm{Ba}, \mathrm{Sr}) \mathrm{TiO}_{3}$ glass-ceramics, J. Am. Ceram. Soc. 94 (2011) 1805-11. 


\section{Figure captions}

Fig. 1. (a) $\mathrm{XRD}$ patterns of $\mathrm{Ba}_{0.3} \mathrm{Sr}_{0.7} \mathrm{TiO}_{3}$ ceramics prepared by conventional sintering and spark plasma sintering. (b) Enlargement of diffraction peaks at $(2,0,0)$ and $(2,1,1)$ crystallographic plane.

Fig. 2. SEM micrographs on polished and thermal-etched surfaces of $\mathrm{Ba}_{0.3} \mathrm{Sr}_{0.7} \mathrm{TiO}_{3}$ ceramics prepared by (a) conventional sintering and (c) spark plasma sintering. Fracture surface of $\mathrm{Ba}_{0.3} \mathrm{Sr}_{0.7} \mathrm{TiO}_{3}$ ceramics prepared by (b) conventional sintering and (d) spark plasma sintering.

Fig. 3. TEM micrographs of $\mathrm{Ba}_{0.3} \mathrm{Sr}_{0.7} \mathrm{TiO}_{3}$ ceramics prepared by (a) conventional sintering and (b) spark plasma sintering.

Fig. 4. Temperature dependence of dielectric constant and dielectric loss at various frequencies for $\mathrm{Ba}_{0.3} \mathrm{Sr}_{0.7} \mathrm{TiO}_{3}$ ceramics prepared by (a) and (b) conventional sintering; (c) and (d) spark plasma sintering. The enlarged figure in (c) shows the detailed information between $145 \mathrm{~K}$ to $180 \mathrm{~K}$.

Fig. 5. $P-E$ loops at room temperature and $60 \mathrm{~Hz}$ for $\mathrm{Ba}_{0.3} \mathrm{Sr}_{0.7} \mathrm{TiO}_{3}$ ceramics prepared by (a) conventional sintering and (b) spark plasma sintering.

Fig. 6. SEM micrographs on the fracture surface of $\mathrm{Ba}_{0.3} \mathrm{Sr}_{0.7} \mathrm{TiO}_{3}$ ceramics after dielectric breakdown. (b) (d) Enlargement of the region marked by black box on the left, respectively.

Fig. 7. Electrical energy storage densities as a function of electric field for $\mathrm{Ba}_{0.3} \mathrm{Sr}_{0.7} \mathrm{TiO}_{3}$ ceramics prepared by conventional sintering and spark plasma sintering. 


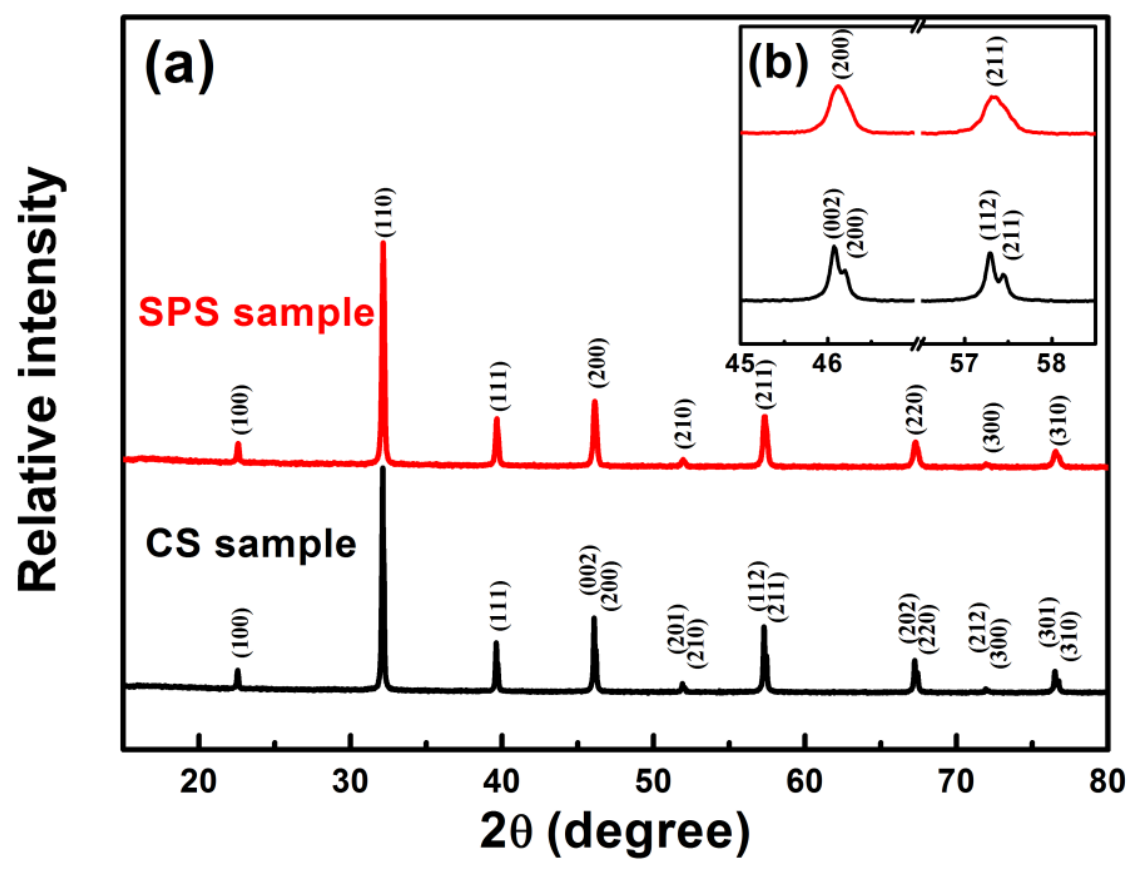



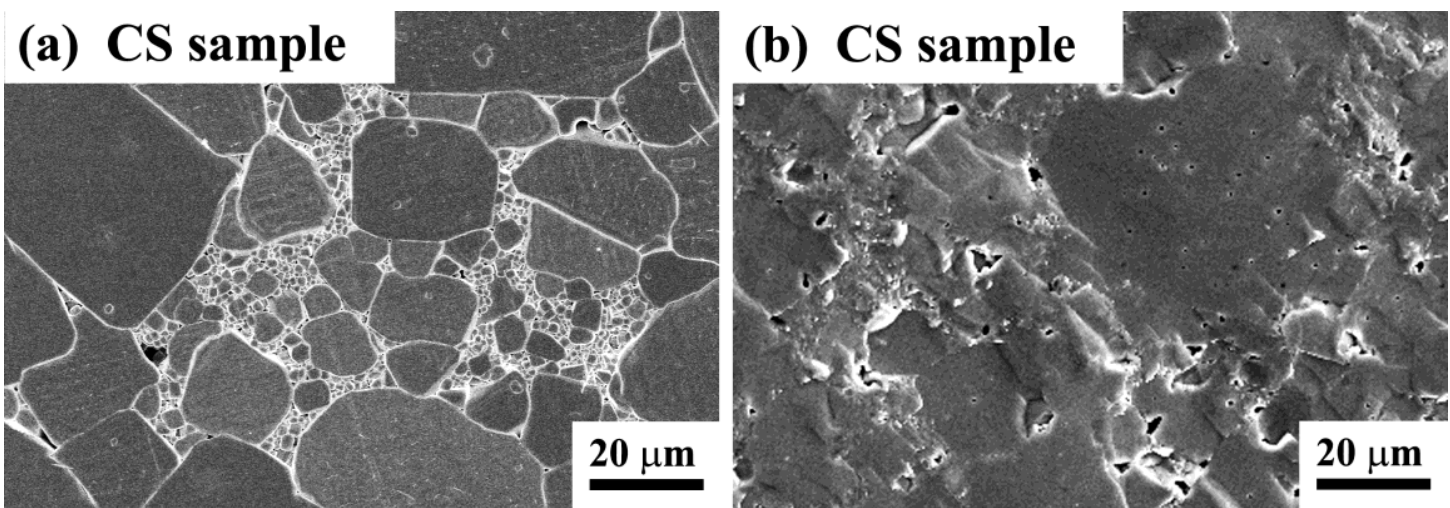

(c) SPS sample

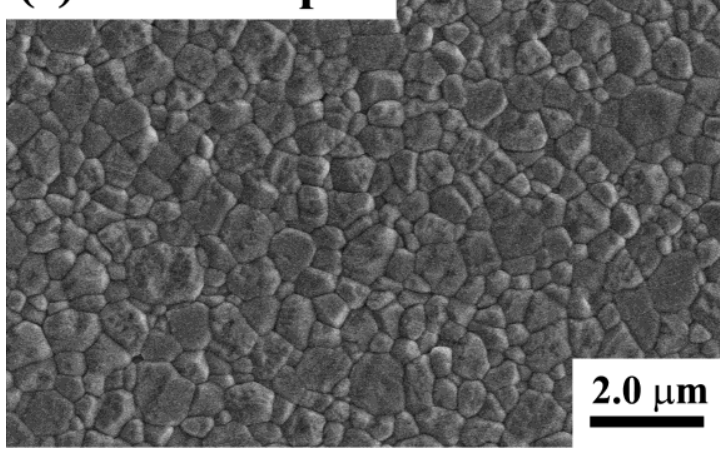

(d) SPS sample

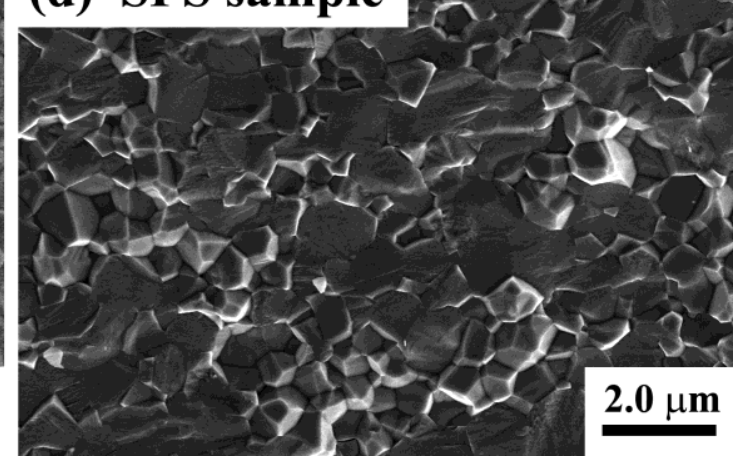


(a) CS sample

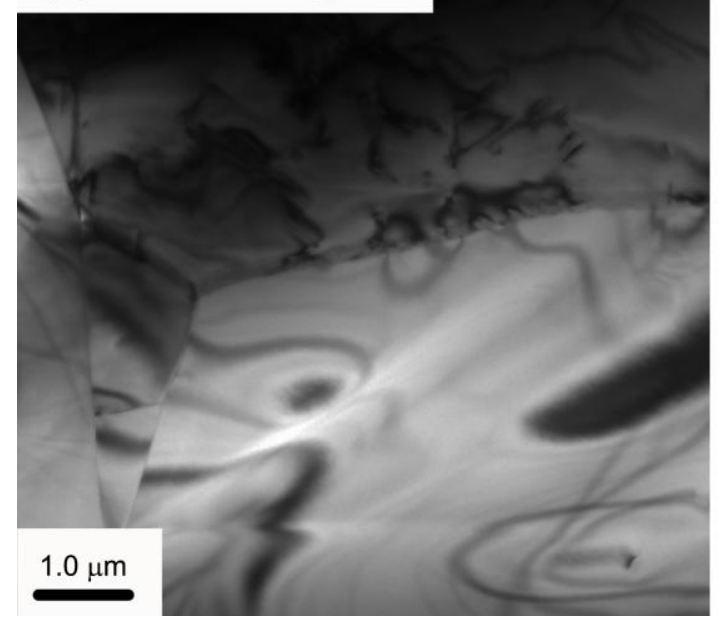

(b) SPS sample

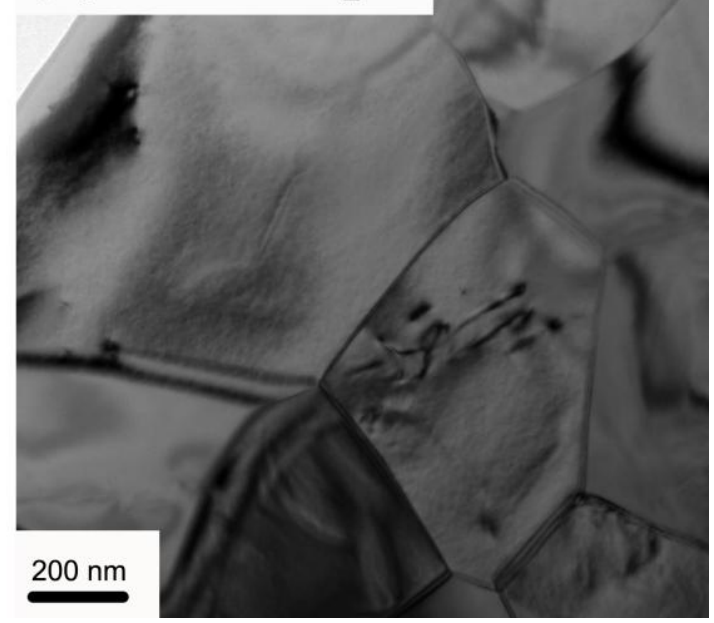



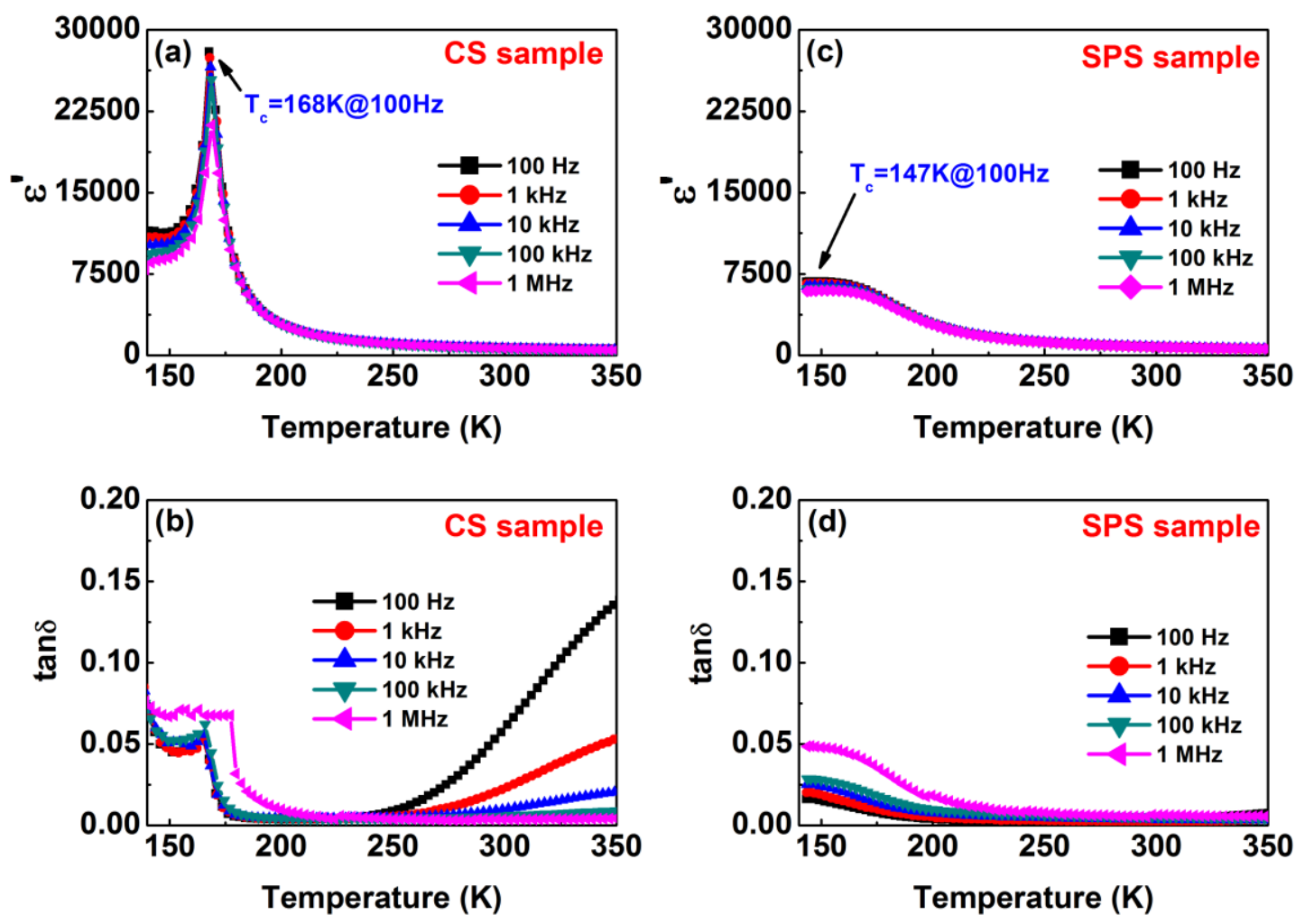

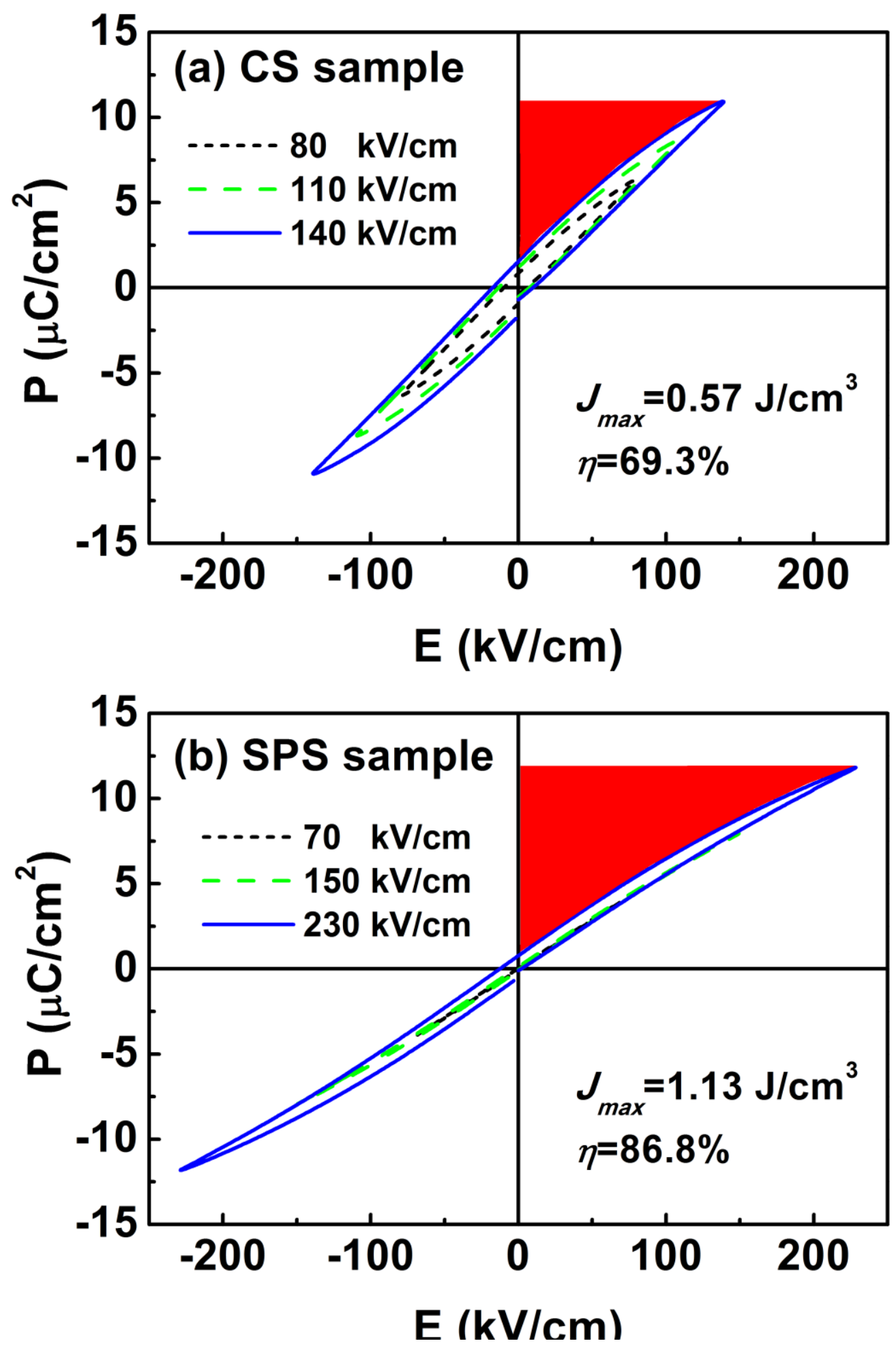
(a) CS sample

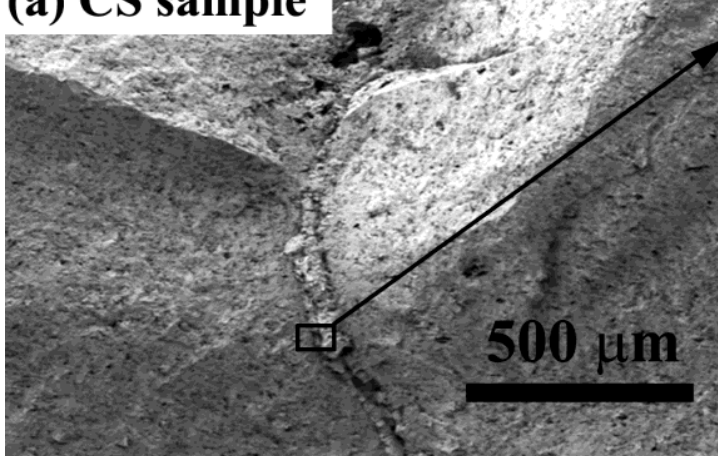

(c) SPS sample (b) CS sample

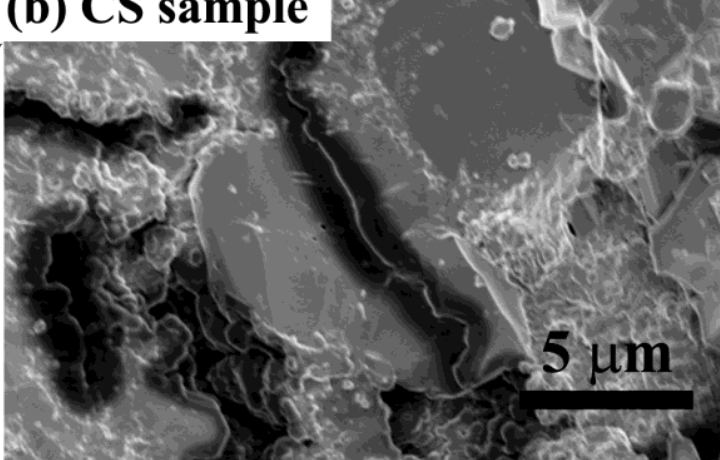

(d) SPS sample 


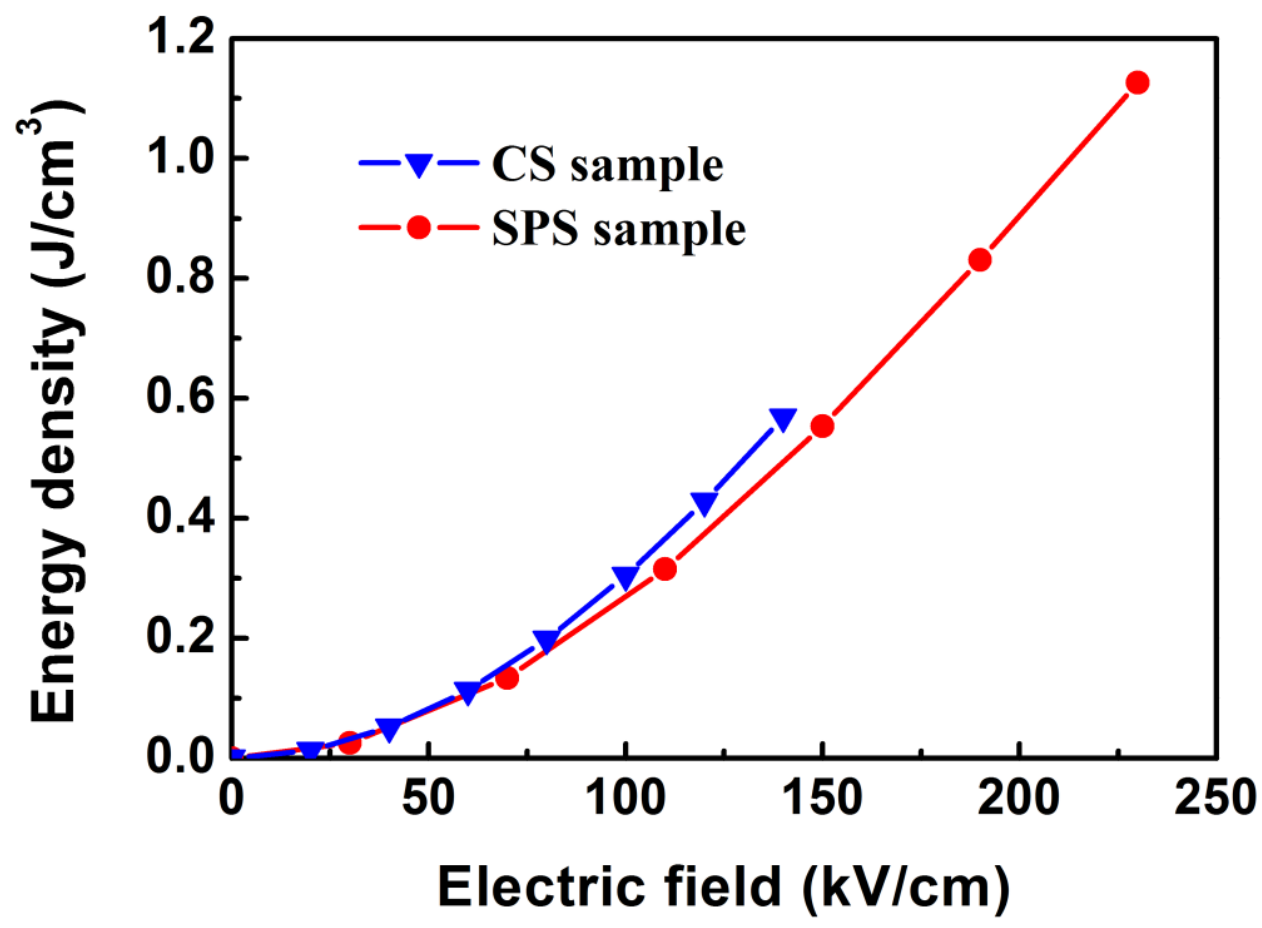

